\title{
Woody energy crops in the southeastern United States: Two centuries of practitioner experience ${ }^{\text {ts }}$
}

\author{
Keith L. Kline ${ }^{a, *}$, Mark D. Coleman ${ }^{b, 1}$ \\ a Oak Ridge National Laboratory, Environmental Sciences Division, Oak Ridge, TN 37830-6038, USA \\ ${ }^{b}$ USDA Forest Service, Southern Research Station, 241 Gateway Dr., Aiken, SC 29803, USA
}

\section{A R T I C L E I N F O}

Article history:

Received 18 November 2009

Received in revised form

29 March 2010

Accepted 31 May 2010

Available online $\mathrm{xxx}$

Keywords:

Short-rotation woody crops

Hardwood plantations

Productivity

Southern pine plantations

Commercial production costs

Bioenergy feedstocks

\begin{abstract}
A B S T R A C T
Forest industry experts were consulted on the potential for hardwood tree species to serve as feedstock for bioenergy in the southeastern United States. Hardwoods are of interest for bioenergy because of desirable physical qualities, genetic research advances, and growth potential. Yet little data is available regarding potential productivity and costs. This paper describes required operations and provides a realistic estimate of the costs of producing bioenergy feedstock based on commercial experiences. Forestry practitioners reported that high productivity rates in southeastern hardwood plantations are confined to narrow site conditions or require costly inputs. Eastern cottonwood and American sycamore grow quickly on rich bottomlands, but are also prone to pests and disease. Sweetgum is frost hardy, has few pest or disease problems, and grows across a broad range of sites, yet growth rates are relatively low. Eucalypts require fewer inputs than do other species and offer high potential productivity but are limited by frost to the lower Coastal Plain and Florida. Further research is required to study naturally regenerated hardwood biomass resources. Loblolly pine has robust site requirements, growth rates rivaling hardwoods, and lower costs of production. More time and investment in silviculture, selection, and breeding will be needed to develop hardwoods as competitive biofuel feedstock species. Because of existing stands and fully developed operations, the forestry community considers loblolly pine to be a prime candidate for plantation bioenergy in the Southeast. (c) 2010 Elsevier Ltd. All rights reserved.
\end{abstract}

\section{Background}

U.S. Public Law 110-140 mandates that biofuel production increase from $34 \mathrm{hm}^{3}$ in 2008 to $136 \mathrm{hm}^{3}$ in 2022, including $60.6 \mathrm{hm}^{3}$ of "advanced cellulosic biofuel" [1]. The U.S. Department of Energy set goals for cellulosic biofuel and feedstocks, including short-rotation woody crops, that imply a delivered feedstock price below $55 \$ \mathrm{Mg}^{-1}$ [2]. Federal, state, and academic organizations are cooperating through regional partnerships to help address the challenges of bioenergy production [3]. Feedstock partnerships are working to quantify opportunities for feedstock production in each of five

\footnotetext{
is This manuscript has been co-authored by UT-Battelle, LLC, under Contract No. DE-AC05-00OR22725 with the U.S. Department of Energy. The United States Government retains and the publisher, by accepting the article for publication, acknowledges that the United States Government retains a non-exclusive, paid-up, irrevocable, world-wide license to publish or reproduce the published form of this manuscript, or allow others to do so, for United States Government purposes.

* Corresponding author. Tel.: +1 865574 4230; fax: +1 8655762943.

E-mail addresses: klinekl@ornl.gov (K.L. Kline), mcoleman@uidaho.edu (M.D. Coleman).

${ }^{1}$ Present address: Department of Forest Resources, University of Idaho, Moscow, ID 83844-1133, USA. 0961-9534/\$ - see front matter @ 2010 Elsevier Ltd. All rights reserved.
} doi:10.1016/j.biombioe.2010.05.005 
regions in the continental United States [3,4]. This paper discusses the hardwood growth potential in the southeastern region, an area south and inclusive of Kentucky and Virginia to east Texas.

In the southeastern United States, biomass is presently the most promising renewable-energy resource [5]. Climate and soils favor abundant biomass production, and more than half of the region is covered in forests. More than 80 million hectares of southeastern timberland produce about $60 \%$ of U.S. timber products. In addition to forestland, there are more than 2 million hectares of idle farmland in the Southeast that could potentially be converted to woody energy crops [6]. Furthermore, the forest industry is highly developed in this region and already operates efficient pine production on a commercial scale $[7,8]$. While there is extensive experience with pine in the region, much less experience and data are available on potential productivity for hardwoods.

Hardwoods are of special interest as potential feedstock for a biofuel industry because of their high rates of production, physical characteristics favorable for some energy-conversion processes, and recent progress with genetic mapping [9]. Pine has received less attention as a feedstock for conversion to liquid transportation fuels (e.g., ethanol) because relatively high levels of secondary chemicals in pine create impediments for biochemical conversion. However, traditional and advanced thermochemical conversion facilities in the region [6] suggest the market is favoring thermochemical over biochemical conversion of pine. Choice of feedstock will ultimately depend on price and availability.

Collection of more reliable and consistent information on the potential scale-up of woody crop production for bioenergy, including data on yields, commercial operation costs, and sustainability, is a current priority of the research community [4]. Obtaining high quality data can present many challenges. Monitoring requires several growing seasons before yields can be quantified. Fluctuating markets and public interest make it difficult to maintain commitment for silvicultural prescriptions. These logistic obstacles, as well as inconsistent site conditions, result in highly variable results. Furthermore, available data on hardwood productivity are based primarily on research station sites rather than larger scale, operational experiences, which makes it difficult to draw useful conclusions about commercial woody-energy-crop production potential. Nevertheless, timber companies operating in the region have a rich history in developing hardwood plantation management.

\section{Purpose}

The present effort sought to record knowledge of industrial practitioners with professional experience in the development of operational hardwood plantations in the southeastern United States. Interviews provided insights on the limitations, opportunities, and potential productivity from hardwoods in the region. Practitioners from forest-product companies have researched the productivity potentials of a range of tree species during the past 50 years. Their combined expertise was applied to assess the potential for hardwood species as energy crops, focusing on the following areas:
- Identifying favorable hardwood energy-crop species for the Southeast

- Identifying what data are available on hardwood productivity in the region

- Providing best estimates of production rates for southeastern hardwoods

- Describing silvicultural practices required to achieve predicted production rates

- Estimating costs of implementing those practices

- Comparing present and projected hardwood productivity rates to standard loblolly pine silviculture as an alternative energy crop

- Assessing data gaps and proposing key areas where further research is required

\section{Methods}

The approach involved scoping, interviews, compilation, and comparative analysis. The scoping began with identifying practitioners with extensive practical experience growing hardwoods for commercial purposes in the region. This was done through iterative referrals beginning with known experts. Another scoping task was to determine species and key variables to study. The list of species was initially developed from the literature and modified with input from practitioners. A template was developed to provide consistency in covering topics and a standard structure for each interview.

Interviews were conducted from January to May, 2007 with a standard questionnaire. Thirteen practitioners with more than 250 years of aggregate forestry experience in the Southeast were interviewed in seven individual sessions and two group sessions. A mixture of telephone and face-to-face interviews was conducted. Results from each interview were documented and subsequently shared with interviewees, who were invited to review the results and provide corrections and comments. Productivity estimates made by the 13 practitioners were tabulated along with any qualifications from those interviewees.

To compare productivity estimates, it was necessary to qualify environmental and silvicultural practices in a standardized way because site conditions and management practices largely control productivity. Climate in the Southeast was easily defined by geography. Fine-scale site variation was standardized on the basis of soil characteristics. Soils strongly influence the establishment, growth, and productivity of trees and often determine (a) which species are most appropriate for a site and (b) what treatments are necessary. To normalize productivity estimates, soil groupings were selected from the forest-soil classification matrix developed by the Cooperative Research in Forest Fertilization (CRIFF) program at the University of Florida [10]. The CRIFF soil groupings are based on easily recognizable features that can be classified in the field, such as depth to clay and water table. All of the interviewees were familiar with this type of soil classification for stratifying forestland.

Silviculture practices (soil preparation, fertilization, thinning, etc) also affect productivity. To further normalize productivity estimates, a standard silvicultural approach was 
Box 1: Standard Silviculture Practices for Comparing Hardwood Productivity

Site preparation, planting density, and treatment require knowledge of soils and species to be planted. The first essential step is to understand the soil and select an appropriate species and variety for the site. Soils should be tested and treated, if required, to bring $\mathrm{pH}$ and nutrients to minimal acceptable ranges at planting. Other steps follow.

a) Site preparation includes clearing debris as necessary; up-soil or chisel plow (in two directions, if needed) to break hardpan; disc or double disc for clean, level planting; form raised beds if high spring moisture will be a problem for the species selected; and treat with appropriate herbicide in season (JulySeptember) prior to planting.

b) Establishment by mechanized planting is preferred to ensure proper depth and good closure; timing is important-one must plant during the late dormant season and at an appropriate time to take advantage of spring rains; targeted herbaceous control should be used for the first two seasons, as needed (usually, targeted control will be needed twice in year one and at least once more in year two) to control competition; and the necessary steps should be taken to avoid drought or flood during the initial year to ensure proper establishment. Typical spacing is $3.7 \times 3.7 \mathrm{~m}$ in better soils and $2.7 \times 2.7 \mathrm{~m}$ for upland or poor soils.

c) Monitoring and management include inspection and control for pests and competition and verification that growth targets are being met (and if not, determining why); depending on site and species, one additional fertilizer treatment is often recommended at mid-rotation ( 5 to 8 years; typically $110 \mathrm{~kg}$ ha- 1 of $\mathrm{N}$ but actual composition could vary for given site conditions; usually at least $\mathrm{N}$ is needed)

developed (see Box 1). Practitioners were asked to estimate productivity on the basis of this prescription and to describe any revisions necessary to achieve productivity estimates for each species.

Consistent with the literature [11], all practitioners noted that the eucalypts require far fewer silvicultural inputs, so a parallel but significantly different standard approach was developed for the eucalypts (see Box 2). The standardized set of operations and treatments, combined with the CRIFF soil tables, allowed productivity for different species and sites to be compared in terms of a common baseline for site preparation, stand establishment, weed control, fertilization, etc.

\section{Compilation of data}

Each interview produced a list of promising species, growing ranges, notable site requirements, costs, and estimates of present and future productivity averaged over a given rotation period. The yields assume that the standard silvicultural practices (Boxes 1 and 2) are followed. The high and low yields
Box 2: Silviculture Practices Typical for Eucalypts

- During site preparation, treat the soil, if required, to bring $\mathrm{pH}$ to an acceptable range at planting. Form raised beds if high water will be a problem. Treat with an appropriate herbicide to control weeds during the first year.

- During establishment, mechanized planting is preferred to ensure proper depth and good closure; timing is important-one should plant to take advantage of rains. Use targeted herbaceous weed control as needed. Avoid drought in first year.

- Once established, eucalypts perform well with minimal additional inputs.

reflect a range of typical site conditions that are described for each species. Yields were converted from local units on the assumption that green wood contained $50 \%$ moisture on a total mass basis. The responses from all interviewed practitioners were averaged by species as $\mathrm{Mgha}^{-1} \mathrm{y}^{-1}$. Reported results from smaller trials and research data were segregated from largescale commercial production data. A similar process was used to develop average reported costs in 2006 dollars for plantation establishment and treatments. Costs for implementing the recommended silvicultural practices (Boxes 1 and 2) were estimated, and any exceptions were noted for a given species.

\section{Results}

The interviews produced several areas of agreement and a few differences of opinion. Every respondent replied to the first query in the standard questionnaire ("What hardwood species is best for biomass production (and where) in the Southeast?") with various forms of, "It depends." Practitioners consistently acknowledged a need to select and improve cultivars for the specific needs of commercial operations, noting that those needs will vary depending on site characteristics, markets, rotation, harvest technology, qualities desired in final products, and other factors. They also agreed that experience with hardwoods was limited and that current commercial productivity is low compared to future potential because there is a lot of room for improvement in management and genetics [8,11-13]. Species that are better understood in terms of cultivar genotypes and traits are more likely candidates for rapid improvement and commercial applications in the near to medium term $[9,14,15]$. Practitioners believed that the hardwood species best positioned for future commercial production are currently sweetgum for broad regional applications and eucalypts for the coastal zone, where risks of freezing are minimal. Scientific advances with poplar make it a strong potential future feedstock candidate for biochemical conversion, particularly if cultivars are produced to tolerate marginal site conditions [14-16]. Although the interviews focused on hardwoods, practitioners consistently recommended that loblolly pine be given more consideration as a potential bioenergy feedstock. Indeed, despite the specificity of the initial question, "What is the best hardwood species for biomass in the Southeast?", many of the respondents 
Table 1 - Mean annual production by species in megagrams of dry equivalent stem weight per hectareyear: aggregate interview responses.

\begin{tabular}{lccc}
\multirow{2}{*}{ Species } & \multicolumn{3}{c}{ Dry $\mathrm{Mg} \mathrm{ha}^{-1} \mathrm{y}^{-1}$} \\
\cline { 2 - 4 } & Low & High & Average \\
\hline Mixed upland hardwoods & 1 & 4 & 3 \\
Mixed bottomland hardwood & 7 & 9 & 8 \\
Oak, upland & 2 & 4 & 3 \\
Cottonwood & & & \\
$\quad$ Poplar hybrid trials & 9 & 20 & 15 \\
$\quad 3$ & 6 & 5 \\
Pycamolar hybrid plantation & 7 & 11 & 9 \\
Sweetgum trials & 7 & 12 & 9 \\
Sweetgum & 4 & 8 & 6 \\
Aspen hybrids & 9 & 12 & 10 \\
Eucalyptus (average of various species) & 18 & 25 & 22 \\
Loblolly pine & 8 & 10 & 9 \\
\hline
\end{tabular}

answered, "Why not pine?" underscoring their belief that the prevalence of pine plantations in the Southeast and the broad accumulated knowledge about the management of those plantations [12] made that species a prime candidate for biofuel feedstock production.

The uncertain structure of developing bioenergy markets was a regular discussion point with practitioners because bioenergy crop specifications are dependent on conversion technologies. Many participants believed that there was not yet enough information on desired feedstock characteristics to make a well-founded recommendation for a preferred hardwood species for biofuels.

Table 1 presents the aggregate interview responses for yields. These yield values were determined by asking the respondents to provide their experience-based estimates of productivity of each species, as constrained by a standard set of assumed silviculture practices and the preferred soil range from the CRIFF soil tables (preferred and tolerable soil ranges varied somewhat from species to species). The respondents were asked for a range (low, high, average) that they had experienced for each species. All the lows cited by the individual respondents for a given species were averaged to get the average "low" estimate for that species shown in Table 1. A similar procedure was followed to determine the "average" and "high" estimates for each species.

Estimated yields for eucalypts stand out in terms of growth potential but are based on relatively limited operations in Florida. Trial results with hybrids also appear promising but differ greatly from larger scale experiences. The narrow gap between trials and plantations for sweetgum relative to poplar demonstrates why practitioners favor this species as more reliable across the Southeast.

Table 2 summarizes descriptive information, including geographic range, advantages, and limitations, for each species. Additional information brought forward by the practitioners is summarized below by species.

\subsection{American sweetgum (Liquidambar styraciflua L.)}

American sweetgum, also known as redgum and liquidambar, is a medium to large tree adapted to a wide range of soils. It is one of the most common southern hardwoods. Its range includes Kentucky, Tennessee, Virginia, and North Carolina except for the higher elevations of the Appalachian Mountains and it extends into northern Florida and eastern Texas with the exception of coastal Louisiana. Sweetgum is tolerant of sites with low moisture and nutrient availability [17] but grows best in moist, somewhat acidic loam or clay soils and has moderate salt tolerance. Commercial planting is found primarily in mid-coastal plains north of Florida from east Texas to Virginia. Survey participants ranked sweetgum as a top choice among current hardwood species for potential commercial bioenergy production because of robust site requirements and despite its relatively low growth rate in comparison to other candidate species. Production rates quoted by practitioners are comparable to those reported in the literature [18]. Some experts estimated that future sweetgum growth rates could nearly double with genetic improvements and better silviculture. Sweetgum requires less management attention and inputs than other hardwoods but it is not recommended for very short rotations because growth during the first few years is slow [19].

\subsection{Eastern cottonwood (Populus deltoides Bartr.)}

Eastern cottonwood is a fast growing poplar and one of the largest North American hardwood natives. In natural conditions, cottonwood is often found where seasonal-floodreplenished nutrients aid seedling establishment, rooting of fallen branches, and rapid growth and development. Plantation cultivation in the Southeast requires intensive site preparation and management during the establishment stage for acceptable survival [8]. Site requirements currently limit maximum production to mesic, nutrient rich, bottomlands. Cottonwood's breeding potential offers great opportunities for developing site-adapted genotypes [20]. High initial growth rates tend to taper off after 4-8 years, offering a potential for short-rotation harvests, but constraints of suitable soils and pest susceptibility limit widespread commercial application.

\subsection{Hybrid poplar (Populus trichocarpa Torr. \& Gray $\mathbf{x}$ deltoides)}

Populus is a large and well-studied genus including cottonwoods, poplars, and aspens. The Interamerican Poplar (Populus trichocarpa $x$ deltoides) or " $\mathrm{T} \times \mathrm{D}$ " hybrids have been the most successful in hardwood plantations in the northern half of the southeastern region and share many of the characteristics of cottonwood. Further work is needed to develop suitable clones for the Southeast. Euroamerican hybrids ( $P$. deltoides $\times$ nigra L.) and Eurasian hybrids (P. nigra $\times$ maximowiczii A. Henry) have not met notable success in the southeastern United States because of putative (but poorly documented) disease susceptibility. P. trichocarpa is currently the only tree species with complete genetic sequencing [9]. Researchers hope this sequencing will facilitate more rapid development of clones with desired traits for bioenergy [14]. However, productivity has generally been lower than expected in plantations partly because of pest and disease problems, as well as a requirement for high site resource availability. 
Table 2 - Range, advantages, and limitations for commercial biomass tree species in the southeastern United States.

\begin{tabular}{|c|c|c|c|}
\hline Species & Preferable Range & Advantages & Limitations \\
\hline Sweetgum & $\begin{array}{l}\text { Uplands throughout } \\
\text { the Southeast }\end{array}$ & $\begin{array}{l}\text { + Native species } \\
+ \text { Most adaptable hardwood } \\
\text { across region } \\
+ \text { Fairly well known/studied } \\
+ \text { Improvement likely in medium term }\end{array}$ & $\begin{array}{l}\text { - Moderate productivity } \\
\text {-Limited commercial } \\
\text { experience }\end{array}$ \\
\hline Eucalypts & $\begin{array}{l}\text { Florida and South Coastal Plain } \\
\text { (hardiness zone } 8 \mathrm{~b} \text { or higher to } \\
\text { reduce freeze damage) }\end{array}$ & $\begin{array}{l}\text { + Highest growth rates } \\
\text { + Adaptable to marginal sites } \\
\text { + Multiple products/markets } \\
\text { + Improvement likely in near term }\end{array}$ & $\begin{array}{l}\text {-Exotic species } \\
\text {-Frost vulnerable } \\
\text {-Water requirements }\end{array}$ \\
\hline $\begin{array}{l}\text { Cottonwood and } \\
\text { poplar hybrids }\end{array}$ & $\begin{array}{l}\text { Alluvial bottomlands and } \\
\text { low river terraces }\end{array}$ & $\begin{array}{l}\text { + Potential for high growth rates } \\
\text { under right conditions } \\
+ \text { Extensive genetic research } \\
+ \text { Existing commercial stands } \\
+ \text { Improvements likely in } \\
\text { medium term }\end{array}$ & $\begin{array}{l}\text { - Narrow site requirement } \\
\text { - Variable productivity } \\
\text { - Requires intensive management } \\
\text { and inputs } \\
\text { - Not drought tolerant }\end{array}$ \\
\hline Sycamore & Well drained bottomlands & $\begin{array}{l}\text { + Fast growing first } 2 \text { to } 3 \text { years } \\
\text { (but not a recommended } \\
\text { species with current cultivars) }\end{array}$ & $\begin{array}{l}\text { - Narrow site requirement } \\
\text { - Chronic disease problems } \\
\text { - Not drought tolerant }\end{array}$ \\
\hline $\begin{array}{l}\text { Oak (red, cherry bark, } \\
\text { and black) }\end{array}$ & $\begin{array}{l}\text { Upland sites in cooler zones } \\
\text { (hardiness zone } 8 \text { - north) }\end{array}$ & $\begin{array}{l}\text { + Native adapted to marginal soils } \\
+ \text { High-value products with biomass } \\
\text { as residue } \\
+ \text { Can outperform others on sites } \\
\text { with shallow topsoil } \\
\text { and heavy subsoil. }\end{array}$ & $\begin{array}{l}\text { - High costs of initial establishment } \\
\text { - Slow growth } \\
\text { - Limited data on genetics and silviculture } \\
\text { - No commercial experience }\end{array}$ \\
\hline Hybrid aspen & $\begin{array}{l}\text { Upland sites in cooler zones } \\
\text { (hardiness zone } 8 \text { - north) }\end{array}$ & $\begin{array}{l}+ \text { High growth potential } \\
+ \text { Tolerant to range of sites, } \mathrm{pH}, \\
\text { drought }\end{array}$ & $\begin{array}{l}\text { - Requires more study } \\
\text {-In early stages of research }\end{array}$ \\
\hline $\begin{array}{l}\text { Willow, river birch, } \\
\text { red maple, } \\
\text { yellow poplar, and } \\
\text { others }\end{array}$ & To be determined & $\begin{array}{l}+ \text { Potentially fast growing } \\
+ \text { To be determined }\end{array}$ & $\begin{array}{l}\text { - Relatively unknown in the Southeast } \\
\text { - Research needed }\end{array}$ \\
\hline $\begin{array}{l}\text { Mixed natural } \\
\text { hardwoods }\end{array}$ & $\begin{array}{l}\text { Existing stands } \\
\text { throughout region }\end{array}$ & $\begin{array}{l}\text { + More than } 53 \times 106 \text { hectares of } \\
\text { mature stands accessible and } \\
\text { harvestable } \\
+ \text { Mixed products and markets } \\
+ \text { No establishment or cultivation } \\
\text { costs }\end{array}$ & $\begin{array}{l}\text { - Heterogeneous sizes, types, etc. } \\
\text { complicate harvest and market options } \\
\text { - Typical access more costly and difficult }\end{array}$ \\
\hline Loblolly pine & $\begin{array}{l}\text { Established pine } \\
\text { plantations and } \\
\text { native pine areas } \\
\text { throughout region }\end{array}$ & $\begin{aligned}+ & \text { Well developed operations } \\
& (50+\text { years of intense R\&D) } \\
& \text { with } 13 \times 106 \text { hectares in the } \\
& \text { southeastern United States } \\
+ & \text { Better productivity than most } \\
& \text { hardwoods on same sites } \\
+ & \text { Broad genetic potential } \\
+ & \text { Improvements ongoing }\end{aligned}$ & $\begin{array}{l}\text {-Undesired traits for biochemical } \\
\text { conversion to ethanol }\end{array}$ \\
\hline
\end{tabular}

\subsection{American sycamore (Platanus occidentalis L.)}

American sycamore grows rapidly with the range of production rates quoted by practitioners supported by properly managed experimental trials [21]. Its native distribution is primarily confined to riparian areas with high resource availability in the eastern half of the United States. The ideal range for sycamore is limited because of susceptibility to xylella (Pierce's disease for grapes), ceratocystis, and anthracnose disease (Apiognomonia veneta, syn. Gnomonia platani, a family of introduced fungal blights) [22]. Practitioners explained that plantations will perform best in alluvial bottomlands in Tennessee and Virginia, north of the hazard line for xylella (roughly, from USDA plant hardiness zone 6 northward). Initial efforts to breed disease resistance with hybrids have not been sustained and, therefore, have not 


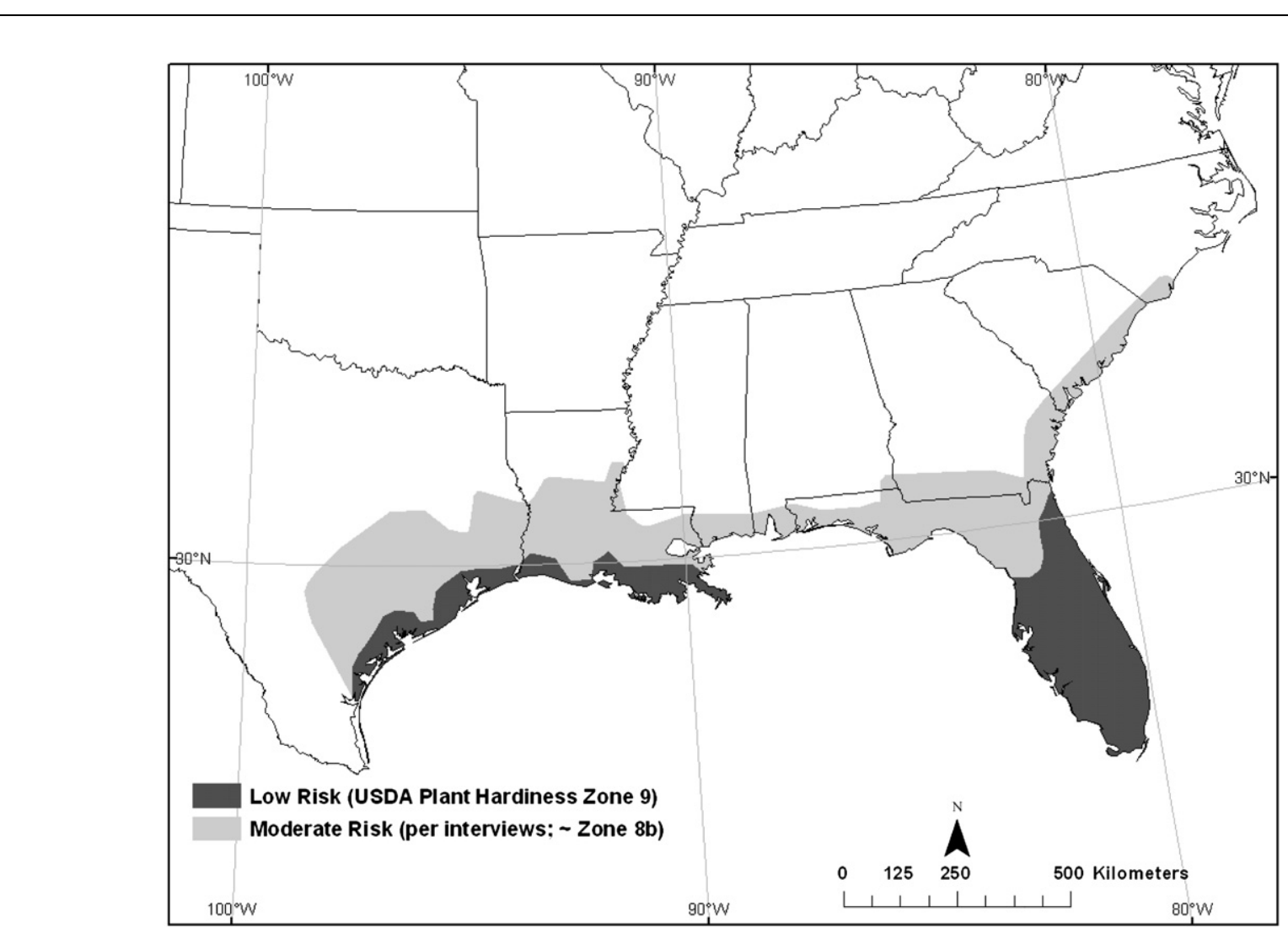

Fig. 1 - The geographic range recommended for eucalypts depended on variety and purpose. To reduce the risk of frost when managing longer rotations for larger stems, a frost free range that roughly coincides with USDA Plant Hardiness Zone 9 was recommended (dark shading). Biomass production for energy was expected to be viable with short rotations extending farther north into Hardiness Zone 8 (light shading). Source: ORNL figure derived from practitioner interviews and Plant Hardiness Zones for the Southeast from the U.S. National Arboretum [50].

achieved desired results in plantation settings. Sycamore requires intensive site preparation; but once it is established, leaf mulch helps control weeds and hold moisture. Its high initial growth rates permit rapid biomass production, especially under short coppiced rotation $[19,20]$.

\subsection{Eucalypts}

Eucalypts are natives to Australia and Asia belonging to three closely related genera: Eucalyptus L'Her., Corymbia Hill \& John., and Angophora Cav. More than 700 species are in the Eucalyptus genera alone, ranging from tall forest trees to short shrubs. Current varieties of eucalypts perform well on moderately well and well drained sites in areas free of frost (see Fig. 1). Eucalypts' growth rates fluctuate with water (and therefore nutrient) availability. When nutrient supply is low, growth can slow to a static state. During periods of high water and nutrient availability, eucalypts' growth rate will surge if the temperature is favorable, resulting in high productivity [23]. Eucalyptus growth and productivity are closely tied to water use, with productivity varying inversely with evaporative demand when growth was not limited by water or nutrient deficit [24]. Eucalypts require minimum phosphorus fertilization but otherwise do well on nutrient-poor soils and can adapt to a wide range of $\mathrm{pH}$. Eucalypts are susceptible to damage from cold temperatures because frost depresses maximum net photosynthesis, although eucalypt clones have been developed with increased frost (but not freezing) resistance. Moreover, because it takes several days for eucalypts to recover from a frost event, the effects of repeated (e.g., diurnal) frosts are cumulative and can produce greater and greater damage [25].

Eucalypts have been established successfully on Florida land degraded by phosphate mining [26]. They do best with proper site preparation, but require less input for establishment than do other hardwoods (see Box 2). In current commercial operations, eucalypts are often planted like loblolly pine in bedded rows about $3 \mathrm{~m}$ apart and spaced at 1.8- to 2-m intervals, resulting in about 200-280 trees ha ${ }^{-1}$. New clones are being selected for high productivity on a broad range of sites and soil conditions with the hope of achieving 30 dry $\mathrm{Mg} \mathrm{ha}^{-1} \mathrm{y}^{-1}$ in appropriate sites within the next decade [27]. Clone cuttings are easy to reproduce and some varieties (Corymbia torelliana and $E$. amplifolia) are reported by practitioners to permit year-round coppicing with good recovery, an unusual and desirable trait. The University of Florida is releasing selected Eucalyptus grandis cultivars, and the State of Florida is supporting development of Eucalyptus plantations for bioenergy [28].

\subsection{Other species}

Practitioners cited several species that have been considered and/or tested because of high growth potential but, at this time, are considered less desirable than those species listed 
above for commercial plantation production in the Southeast. Production rates in this region are largely undocumented for these less-desirable species, which include:

- Red maple (because of difficult silviculture),

- Locust (unimpressive growth and lack of market), and

- River birch (lack of market, multi-stemmed, but could merit further study for bioenergy).

However, the practitioners also identified several species that merit further study to better estimate their potential in future biomass production systems, especially within upland sites north of eucalypts' current range. Among those species warranting more study, hybrid aspen (Populus alba L. $x$ tremula L.) offers potential north of hardiness zone 9 in poorly drained to well drained soils. Hybrid aspen reportedly tolerates a range of $\mathrm{pH}$ and drought, and initial research reported by practitioners led to their estimates that site-appropriate selection offers growth rates of 9-12 dry $\mathrm{Mg} \mathrm{ha}^{-1} \mathrm{y}^{-1}$. Documentation of hybrid aspen performance in the southeastern United States is not available; however, significant genetic variations that have been induced by environmental interactions in other regions [29] suggest that yields could increase significantly with genetic improvements.

Oak (Quercus L.) has received minimal attention for potential genetic improvement and improved silviculture in the southeastern United States. Several varieties, such as Q. falcate (red), Q. velutina (black) and Q. falcate var. pagodaefolia (cherry bark), appear to show promise for relatively rapid growth on appropriate sites [30]. Because oak is highly valued by sawmills, there may be more economic incentive to grow it for multiple products and markets with tops and residues allocated to bioenergy. At present, difficulties and costs to establish oak plantations appear to be major hurdles. Oak silviculture is considered to be more difficult than that of sweetgum or eucalypts because seeds and seedlings are larger and harder to store, handle, and manage and because oak's growth is initially very slow, leading to high costs for establishment, controlling competition, and monitoring young plantations.

Yellow poplar (Liriodendron tulipifera L.) is also known as "tulip poplar". This native to eastern North America grows much faster than sweetgum in some sites but prefers better drained soils and cove-settings in upper coastal plains (northern Alabama and Tennessee). It does not withstand inundation but requires adequate water during summer months to maintain growth. Productivity is somewhat unpredictable but it may be an option that merits consideration on selected upland loamy soils.

Willow (Salix L.) is a genus including 400 species and many hybrids. Although there are species native to the region, willow has received minimal study in the Southeast. Given its promising productivity in other regions, very efficient coppice production systems [31,32], and wide native distribution, it merits further study in the southeastern United States.

Southern pine sustains the world's largest plantation forestry operations. The practitioners surveyed had vast experience and knowledge about pine plantations and expressed a number of reasons why loblolly and slash pine should be considered as a regional bioenergy feedstock. Pine productivity in the Southeast is documented elsewhere [33-36]. Several experts in separate interviews spontaneously questioned the focus on hardwoods and argued that pine should be a top biofuel feedstock candidate in the region because:

- There are 13 million hectares of pine plantations in the Southeast, and 600,000 ha are planted each year.

- The germplasm data bank for southern pine is unrivaled by other species.

- Southern pine productivity has risen by a factor of 4 during the past 60 years [7], and an additional factor-of- 4 increase is possible from genetic improvement and intensified management.

Loblolly (Pinus taeda L.) is capable of rapid growth on a wide range of sites, while slash pine (Pinus elliottii) is also very productive, but has somewhat narrower site requirements. Loblolly and slash pine grow on soils that range from very poorly drained to moderately well drained. Commercial loblolly plantations typically produce from 1 to $5 \mathrm{Mg} \mathrm{ha}^{-1} \mathrm{y}^{-1}$ dry stem biomass, while demonstrated potential under intensive management is $5-12 \mathrm{Mg} \mathrm{ha}^{-1} \mathrm{y}^{-1}[18,35]$.

\section{7. $\quad$ Natural hardwoods and mixed-stand management}

Natural mixed-hardwood stands have average growth rates of about 3 dry $\mathrm{Mg} \mathrm{ha} \mathrm{h}^{-1} \mathrm{y}^{-1}$ in upland sites and 8 dry $\mathrm{Mg} \mathrm{ha}{ }^{-1} \mathrm{y}^{-1}$ in river bottoms [37]. Estimating mixed hardwood productivity is complex but long-term monitoring of permanent plots in the Southeast has facilitated the development of yield models for the region $[37,38]$. There are about 55 million hectares of natural hardwood stands already growing, available, and accessible for collection [39] if the market for the relatively low density of heterogeneous products justified the costs of harvest, handling and transport. These forests could be much more productive and valuable with small investments in silviculture [40,41]. For bioenergy feedstock, questions about composition from mixed species remain to be answered; but if processes do not require homogenous feedstock, natural forests offer an option to increase biomass supplies more quickly and with lower costs than by establishing new hardwood plantations and waiting a period of years before harvest.

Natural upland forests left to grow 60 years produce 134 dry $\mathrm{Mg} \mathrm{ha}^{-1}$ and are economically viable to harvest [37]. On average, they offer about a $7 \%$ internal rate of return on minimal investment and costs. The most economical management approach is to clear-cut and then generate another even-aged forest, although social and environmental considerations may limit this option. No treatments are required because natural mixed hardwoods come back voluntarily. However, there are opportunities to dramatically increase value and productivity with timed selective thinning and fertilizer [37]. The silvicultural concept is to speed up the self-thinning that a natural stand would follow for selected (most desirable) species and stems [37,42]. Significant stand improvement is possible through early interventions (the first 1-15 years), selectively removing lesser value stems to release higher value trees. Forest thinning procedures for improved stand structure and fuel reduction (wildfire mitigation) could generate a low-cost source of biomass feedstock [43]. 


\section{Impediments to hardwood plantations}

Practitioners agreed that current hardwood varieties did not appear economically viable for plantation production in the Southeast, with the exception of eucalypts in a restricted range. Many of the hardwood plantations established during the past two decades have not been managed according to standard silviculture guidelines because the management costs could not be justified.

\subsection{Markets}

The biggest hurdle for hardwood plantations is economics. Costs, discussed below, are relatively high compared to demand and price incentives. There is not a plausible nearterm scenario with prices that justify a land owner's investing significant funds in establishing a hardwood plantation for biofuel alone, given the existing supply potential from other sources (residues, wastes, and existing mixed stands). Without strong market signals, it is difficult to justify the large fixed investments and ongoing costs for management over several years before any return is possible. The region already harvests $70-80 \mathrm{Tg}^{-1}$ on a dry basis for pulp and paper [44] in addition to volumes of hardwoods for poles and other timber products, offering potential for conversion or integration and expansion of the existing industry into more diversified products, including bioenergy. If genetic research paired with biofuel-conversion technologies results in specialized tree varieties suited for energy production, it might alter the prognosis. The fact remains that foreseeable prices for energy feedstocks are lower than prices for feedstocks destined for other products, including pulp and timber. Landowners will need incentives or guarantees prior to making large investments in a new crop and technology [43].

\subsection{Local regulation and environmental issues}

A number of environmental concerns arise regarding woodyenergy-crop production systems that may limit deployment through regulation, added costs, or public opposition. Practitioners stated that some woody plants proposed for shortcycle biomass production in Florida faced costly and complex regulatory obstacles associated with State concerns about invasive species. Similarly, there may be resistance to plantations with high water demand in areas where aquifer recharge and water supplies are a concern. For economic benefits to be realized from forest biotechnology, social, environmental and political concerns about risks and dispersion control must be overcome [45]. Other concerns include visual and environmental impacts of harvesting, site degradation through nutrient removal, compaction, and potential hazards from off-site transport of agricultural chemicals. Fulfilling the requirements for sustainable production certification as advocated by many environmental groups may add costs that are not compensated by the marketplace. Environmental issues and public perceptions need to be addressed in early stages of plantation planning to develop proposals that are environmentally sound and supported and accepted by neighboring landowners and citizen groups.

\subsection{Lack of silviculture}

The most common obstacles to commercial hardwood plantation success mentioned by interviewees, after economics, were related to silviculture: inappropriate site-variety selection, inadequate site preparation, inadequate management to ensure first year establishment, etc. Basic silviculture guidelines such as those summarized in Box 1 must be followed to achieve survival and growth rates in the ranges described in Table 1. Of all silviculture practices, the most often cited as a "showstopper" was the lack of timely weed control $[8,19,46]$. As one practitioner put it, "Once an observer 'thinks it's time' [to apply weed control products], it's too late." Plus, crews must be well trained and supervised, or they can kill trees with overspray. Ensuring competition control and adequate water for establishment are critical in the first year for several species, including sweetgum and eucalypts. Even species thought to tolerate vegetative competition will show favorable response to herbicide application [47], demonstrating the need for such treatments to maintain growth.

\subsection{Disease, herbicides, and site-specific issues}

Additional silviculture issues cited as problems were improper planting, moisture problems after planting (too much or too little), improper selection of plant material for site conditions and disease [48]. Recommendations included not moving a variety south of its preferred climate zone because it will likely encounter more pests and disease and being aware of the sensitivity of some species to herbicides (sycamore and cottonwoods have had establishment problems because of residuals from earlier herbicide applications) [46].

\section{Costs}

Reported costs (expressed in 2006 dollars) varied widely with species, planting density, site conditions, and scale of plantation operations and are embodied largely in establishment, treatment, logging and transport. The ranges of costs reported by practitioners for standard silviculture treatments are presented in Table 3 for different levels of production to illustrate how cost per megagram of biomass is affected by production rate.

\subsection{Establishment}

Stand establishment includes site preparation, cultivation of soil into beds (if necessary), cost of seedlings, and planting. Establishment represents the primary cost for a commercial plantation and must be discounted over time. Site preparation and the application of fertilizer and pesticides are often mechanized.

For example, on a per-hectare basis, site preparation for hardwoods may include the following average costs: (1) Basic site cultivation often requires sub-soil chisel which will cost about 250 \$ for a relatively clean site with good drainage; add another 100-150 \$ if the site requires sheering, piling, clearing of debris, leveling etc.; and add 120 \$ if bedding is needed. (2) Initial chemical preparation costs can range from 50 to $130 \$$ as explained below. (3) Seedlings or clones cost 170-250 \$. (4) 
Table 3 - Estimated costs of production for selected species in the Southeast United States aggregated from interviews. Any comparisons should be tempered in consideration of the variables and limitations discussed in the text.

\begin{tabular}{|c|c|c|c|c|c|c|c|}
\hline & & \multicolumn{2}{|c|}{ Sweetgum } & \multicolumn{2}{|c|}{ Cottonwood } & \multicolumn{2}{|c|}{ Pine } \\
\hline & & \multicolumn{2}{|c|}{ Cost range $\left(\$ \mathrm{ha}^{-1}\right)$} & \multicolumn{2}{|c|}{ Cost range $\left(\$ \mathrm{ha}^{-1}\right)$} & \multicolumn{2}{|c|}{ Cost range $\left(\$ \mathrm{ha}^{-1}\right)$} \\
\hline & & $\min$ & $\max$ & $\min$ & $\max$ & $\min$ & $\max$ \\
\hline \multirow[t]{5}{*}{ Year 1} & Site preparation & 247 & 494 & 247 & 988 & 124 & 432 \\
\hline & Planting stock & 185 & 247 & 185 & 247 & 49 & 99 \\
\hline & Planting & 99 & 124 & 99 & 124 & 99 & 124 \\
\hline & Herbicide & 161 & 395 & 161 & 395 & 86 & 173 \\
\hline & Pesticide & & & & 86 & & \\
\hline \multirow[t]{2}{*}{ Year 2} & Herbicide & 86 & 173 & 86 & 173 & & 86 \\
\hline & Pesticide & & & 86 & 86 & & \\
\hline Year 3 & Pesticide & & & & 86 & & \\
\hline \multirow[t]{2}{*}{ Year 4} & Pesticide & & & & 86 & & \\
\hline & Fertilize & & 62 & & 62 & & 62 \\
\hline Year 6 & Fertilize & & 62 & & & & \\
\hline Year 8 & Fertilize & & 62 & & 62 & & 62 \\
\hline Year 10 & Fertilize & & 62 & & & & \\
\hline Year 12 & Fertilize & & 62 & & 62 & & \\
\hline Total & & 778 & 1742 & 865 & 2459 & 358 & 1038 \\
\hline \multicolumn{8}{|c|}{ Product weight basis $\left(\$ \mathrm{Mg}^{-1}\right)$} \\
\hline & High productivity & 13 & 27 & 14 & 40 & 6 & 18 \\
\hline & Low productivity & 31 & 64 & 34 & 94 & 14 & 41 \\
\hline
\end{tabular}

Fertilizer or soil amendments, if needed, range from 60 to 150 \$. (5) Planting costs $100-120$ \$. Thus, the initial investment to establish a hardwood plantation can run from 690 \$ under the least cost scenarios described above up to $1700 \$ \mathrm{ha}^{-1}$ under the high-end scenarios.

\subsection{Treatment}

The initial investment in a hardwood plantation could be lost if weeds are not controlled. Herbaceous-weed control is the most critical treatment in the first year of a hardwood plantation, although that action may not be necessary if the prior history of the land included chemical site preparation. Chemical treatments are typically done at least two more times after the initial site preparation and, more typically, three to four times. Each herbaceous weed control treatment can cost from 50 to $130 \$ \mathrm{ha}^{-1}$, depending on site conditions, labor costs and whether it is done manually, mechanically or with aerial spray. Unlike pine and eucalypts, most hardwoods studied require fertilization to achieve the reported productivity targets. Sweetgum, for example, may need fertilizer every other year, beginning in year four. The annual fertilizer treatments can range from 60 to $100 \$ \mathrm{ha}^{-1}$. Assuming a 12-14 year rotation for sweetgum, these treatments - three weed controls and four fertilizations - would cost about $560 \$$ ha $^{-1}$.

Thus, the total production expenditures could range from 800 to $2500 \$ \mathrm{ha}^{-1}$ for hardwoods. If a plantation produces 5-10 $\mathrm{Mg} \mathrm{ha}^{-1} \mathrm{y}^{-1}$ on a dry basis, the costs could vary from 13 to $100 \$ \mathrm{Mg}^{-1}$ produced, with lower productivity being a key factor for the higher unit costs. Harvest and transportation costs need to be added for a total delivered price. The costs of hardwood plantation production have generally run much higher than industry targets for economically viable operations, which fall in the range of $35-45 \$ \mathrm{Mg}^{-1}$ delivered $[5,43]$. Table 3 shows that only a high-yielding plantation would be economically viable given a target delivered price of $55 \$ \mathrm{Mg}^{-1}$ [2]. This further underscores the importance of selecting plants with high growth potential for specific site conditions.

The costs for logging and transportation are highly variable, depending on the type of equipment used, tree size, and distance to markets. Estimates for average costs ranged from 5 to 10 \$ per green megagram for logging and from 10 to 20 \$ for transportation or about double those values per dry megagram.

Note that cost estimates vary significantly by species and site. Some situations may require additional monitoring, care, and treatments. For example, to ensure survival in the first year during a drought, irrigation may be necessary. And some hardwood species are more likely to require pest controls (i.e., against the cottonwood leaf beetle).

The practitioners stated that, on the basis of their experiences and their current expectations about the needs of hardwood plantations, they believed that the system developed for pine would prove to be much more efficient and less costly because pine requires less site preparation, offers readily available and inexpensive seedlings, and requires only one herbaceous weed control after planting. Furthermore, pine offers more predictable production results.

\section{Discussion}

All the practitioners agreed that the selection of appropriate genetic stock for a given site was crucial. Plantation species and genetics should be adapted to the site conditions and preferably selected from sources that reduce the chances for disease, pest, and hardiness problems. A surprising number of practitioners questioned the research focus on hardwoods, suggesting without a prompt, that loblolly pine was the best-adapted plantation species for biomass in the region. A few practitioners also argued that natural mixed forests should be considered 
and managed for biomass production rather than attempting to apply more costly, conventional plantation systems to hardwoods. These observations reflect the practitioners' qualitative assessments based on their experiences and provide a point of reference for future research. Additional data and resources are required to permit more systematic, quantitative assessments.

The growth rates in Table 1 reflect the practitioners' estimates for productivity while assuming proper silviculture and use of appropriately selected hardwood genetic material for a given site. The high and low productivity estimates reflect variations within a range of suitable sites for a given species. Other published studies have compared growth rates under multiple variables in test plots, including several cases where recommended silviculture is not applied (e.g., no fertilizer or irrigation for establishment). These studies show a range of growth rates that are generally much lower than the estimates in this paper $[18,21,35,49]$. Likewise, during the past 30 years, several hardwood plantations were established and virtually abandoned with minimal silviculture. The productivity rates for such cases can be expected to regress toward the growth rates of natural forests.

The productivity of hardwoods has a measurable relationship with soil and site qualities. Therefore, with sufficient experience and data, site-productivity tables can be developed for hardwood plantations similar to those that now exist for loblolly pine. Based on many years of trials, the productivity of sweetgum has been predicted to fall somewhat below that of pine in the loblolly belt, assuming current varieties and similar levels of inputs. However, site adaptation for both of these species is similar and much broader than the bottomland species like cottonwood and sycamore.

The current state of the forest products industry casts considerable doubts about the role commercial hardwood forest plantations could play in biofuel feedstock supply in the near or medium term, given existing market prices and supplies. Other biofuel resources, such as urban wastes and residues, are likely to be available at lower cost. In the Southeast, millions of hectares of mature natural hardwood stands could also make it difficult for plantations to compete economically in the near and medium terms. Despite these challenges, most practitioners opined that future hardwood productivity could compete with and exceed pine if more intensive and coordinated research and development investments were applied to hardwood forestry in the region.

Many uncertainties exist regarding preferred characteristics for future biofuel feedstocks. Research is ongoing to define optimal chemical and physical characteristics (sugars, lignin resistance to processing, optimization of by-products, and integrated steps to reduce pre-treatment) in conjunction with improved conversion technologies. Simultaneously, research continues to improve the growth characteristics of several hardwood species [43]. New breakthroughs could change assumptions about what feedstock species would perform best in the region.

The interviews highlighted that many species, including sweetgum, eucalypts, and pine, appear to offer promise for significant improvements in productivity (up to $40 \%$ over present average rates) based on traditional varietal selection for a given site. This optimism is based on commercially available technology that could be scaled up in response to market demand. Further improvements in productivity are possible through transgenic efforts to develop hardwood variants that are more drought and disease resistant and cold and herbicide tolerant than are the wild strains or current hybrids. If successful, these efforts could result in significant increases in productivity over the improved varietal yields. Thus, for example, on a site with good soils that currently yields about 9 dry $\mathrm{Mg} \mathrm{ha}{ }^{-1} \mathrm{y}^{-1}$, growth could increase to $13 \mathrm{Mg} \mathrm{ha}^{-1} \mathrm{y}^{-1}$ through varietal (sysgenic) work and up to double that (26 Mg ha $\mathrm{Mg}^{-1}$ ) with transgenic improvements [27]. However, attaining these higher growth rates will most likely also require higher levels of inputs, especially fertilizer.

\section{Conclusions}

In order to discuss or compare productivity estimates, a standard set of good silviculture practices was required. Failure to follow these practices could have significant impact in terms of both reduced survivability of a stand and much lower yields than predicted here. Experts interviewed agreed that hardwood productivity will vary significantly depending on many factors. Some factors can be controlled or managed to varying degrees (genetic selection, site preparation, and inputs, such as weed control, fertilizer, pest control, and irrigation). Other factors are site-specific and dictate management approaches and the selection of species and varieties best adapted to the location. Soils, drainage, and climate are determining factors for selecting appropriate genetic stock.

Current varieties of fast growing species, such as Eastern cottonwood and American sycamore, are unlikely candidates for large-scale biofuel feedstock production because of disease, narrow site requirements, and the demand for limited bottomland soils. The land most readily available for bioenergy crops occurs in more marginal, upland areas. Sweetgum is tolerant of upland sites, is frost hardy, has few pest or disease problems, and grows across a broad range of sites from Virginia to east Texas. However, experience indicates that sweetgum growth rates are relatively low. Eucalypts require low water and nutrient supply and offer high potential productivity but are limited by frost to a narrow strip of the southern Coastal Plain and Florida.

In terms of present forest resources, pine plantations and mixed natural hardwoods dominate the landscape. Loblolly pine is widely grown in the Southeast for fiber and timber. Pine's site requirements and productivity are well documented. The pine industry has developed improved varieties with growth rates rivaling hardwoods at lower costs of production. Because of existing stands and know-how, the Southeastern forestry community considers loblolly to be a prime candidate for commercial bioenergy in the region. Biomass harvests of young pine plantations are additional potential components in an integrated pine-production system capable of generating multiple products, including energy, pulp, and solid-wood products, during the life of the stand. Extensive mature stands of natural mixed forests could also play an important role in future bioenergy feedstock supplies.

\section{Recommendations}

Independent tree farmers and the commercial forestry industry have developed valuable hardwood experiences that 
merit dissemination and offer insights into future research needs. Follow-on work is recommended to develop an efficient system to facilitate cooperation and information exchange among producers, researchers and government agencies. A first step could be to catalogue and provide access to relevant data on hardwood plantation productivity. Further research using consistent measures and data standards is required to verify estimated productivity levels across soil classifications, translate forestry soil groups into standard USDA soil maps, and map out the potential productivity for hardwoods in the Southeast. More investment in selection and breeding is needed for short-rotation plantation hardwoods to become more competitive as biofuel feedstock. Research is needed to systematically improve promising varieties, reduce demands for inputs (production costs), and develop more-efficient practices for managing hardwood plantations and natural forests. Conversion technologies and systems for adapting the plentiful biomass resources contained in southern pine and mixed hardwood forests to the needs of biofuel industries merit further research.

\section{Acknowledgments}

This work was supported by the U.S. Department of Agriculture Forest Service and Oak Ridge National Laboratory (ORNL). ORNL's research was sponsored by the U.S. Department of Energy's Office of Energy Efficiency and Renewable Energy, Office of the Biomass Program, under contract DE-AC0500OR22725 with UT-Battelle, LLC. This paper synthesizes information from regional experts whose contributions were invaluable: Mike Cunningham, Andy Ezell, Bill Hammond, Munroe Jones, Mike Kane, Don Kaczmarek, Greg Leach, Jim Rakestraw, Nathan Ramsey, Daniel J. Robison, Don Rockwood, Randy Rousseau, and Steve Wann. The authors gratefully acknowledge the contributions of colleagues Latha Baskaran, Mark Downing, Robin Graham, Robert Perlack and Lynn Wright of ORNL, along with Zia Haq and John Ferrell of the Department of Energy for supporting this research. We also appreciate the editorial support of Frederick M. O'Hara, Jr., and the comments and suggestions from Christopher Abernathy, Don Rockwood, Erin Wilkerson, and anonymous peer reviewers.

\section{Appendix. Supplementary material}

Supplementary data associated with this article can be found in the online version at doi:10.1016/j.biombioe.2010.05.005.

\section{R E F E R E N C E S}

[1] US Congress. US energy independence and security act of 2007, Public Law Number 110-140, Title II. Available at:. Washington, DC: Government Printing Office http://www. govtrack.us/congress/bill.xpd?bill=h110-6; 2007 [accessed on 23.03.2010].

[2] US Department of Energy. Biomass multi-year program plan. See Table B-1 and Table B-2 for the target grower payment and logistics cost, respectively. Available at:. Washington, DC: Office of Energy Efficiency and Renewable Energy, Office of the Biomass Program http://www1.eere.energy.gov/ biomass/pdfs/mypp_december2009.pdf; 2009 [accessed on 23.03.2010].

[3] Sungrant Initiative - Southeastern Regional Center. Tennessee agricultural experiment station. Southeastern biomass energy feedstock partnership workshop summary, http://www.sungrant.org/NR/rdonlyres/29F0E7FB-8DB14573-B9D6-17A66D5AF865/1041/SEFeedstockfinalreport.pdf [accessed on 23.03.2010].

[4] Biomass R\&D Board Technical Advisory Committee. June 2-3, 2009, meeting, feedstock subcommittee report out. Available at: http://brdisolutions.com [accessed on 23.03 . 2010].

[5] Walsh ME, Perlack RL, Turhollow A, de la Torre Ugarte DG, Becker DA, Graham RL, et al. Biomass feedstock availability in the United States: 1999 state level analysis, http:// bioenergy.ornl.gov/resourcedata/index.html; 2000 [accessed on 23.03.2010].

[6] Ebert J. DOE's cellulosic ethanol funding put to use. Biomass Magazine. Available at: http://www.biomassmagazine.com/ article.jsp?article_id=1357; December 2007 [accessed on 23. 03.2010].

[7] Fox TR, Jokela EJ, Allen HL. The evolution of pine plantation silviculture in the southern United States. In: Rauscher HM, Johnsen K, editors. Southern forest science: past, present and future. Gen Tech Rept SRS-75. Asheville, NC: USDA Forest Service Southern Research Station; 2004.

[8] Stanturf JA, van Oosten C, Netzer DA, Coleman MD, Portwood CJ. Ecology and silviculture of poplar plantations. In: Dickmann DI, Isebrands JG, Eckenwalder JE, Richardson J, editors. Poplar culture in north America. Ottawa, Canada: NRC Research Press; 2001. p. 153-206.

[9] Tuskan GA, DiFazio S, Jansson S, Bohlmann J, Grigoriev I, Hellsten $U$, et al. The genome of black cottonwood, Populus trichocarpa (Torr. \& Gray). Science 2006;313: 1596-604.

[10] Jokela EJ, Long AJ. Using soils to guide fertilizer recommendations for southern pines. Gainesville, FL: School of Forest Resources and Conservation, Florida Cooperative Extension Service, Institute of Food and Agricultural Sciences, University of Florida; 1999 . Available at: http:// www.sfrc.ufl.edu/Extension/soilfert.htm [accessed on 19/6/ 2010].

[11] Rockwood DL, Naidu CV, Carter DR, Rahmani M, Spriggs TA, Lin C, et al. Short-rotation woody crops and phytoremediation: opportunities for agroforestry? Agrofor Sys 2004;61:51-63.

[12] Carter MC, Foster CD. Milestones and millstones: a retrospective on 50 years of research to improve productivity in loblolly pine plantations. For Ecol Manage 2006;227:137-44.

[13] Stettler RF, Zsuffa L, Wu R. The role of hybridization in the genetic manipulation of Populus. In: Stettler RF, Bradshaw HD Heilman PE, Hinckley TM, editors. Biology of Populus and its implication for management and conservation. Ottawa, Canada: NRC Research Press; 1996. p. 87-112.

[14] US Department of Energy. Breaking the biological barriers to cellulosic ethanol: a joint research agenda. DOE/SC-0095. Available at:. Washington, DC: Office of Science and Office of Energy Efficiency and Renewable Energy http://genomicsgtl. energy.gov/biofuels/b2bworkshop.shtml; 2006 [accessed on 23.03.2010].

[15] Gilbert D. The first tree genome is published: poplar holds promise as renewable bioenergy resource, http://www. innovations-report.com/html/reports/life_sciences/report70577.html [accessed on 23.03.2010]. 
[16] Tuskan GA, West D, Davis M, Elam C, Evans R, Bradshaw H, et al. Development and validation of marker-aided selection methods for wood property traits in loblolly pine and hybrid poplar - Final report. 2001. ORNL/TM-2001/41. Oak Ridge National Laboratory, Oak Ridge, TN, USA. This and other technical reports on poplar are accessible from the Bioenergy Information Network at, http://www.ornl.gov/ webworks/ cppr/y2001/rpt/110186.pdf [accessed on 17.06.2010].

[17] Scott DA, Burger JA, Kaczmarek DJ, Kane MB. Nitrogen supply and demand in short-rotation sweetgum plantations. For Ecol Manage 2004;189:331-43.

[18] Coyle DR, Coleman MD, Aubrey D. Above- and below-ground biomass accumulation, production, and distribution of sweetgum and loblolly pine grown with irrigation and fertilization. Can J For Res 2008;38:1335-48.

[19] Davis AA, Trettin CC. Sycamore and sweetgum plantation productivity on former agricultural land in South Carolina. Biomass and Bioenergy 2006;30:769-77.

[20] Dickmann DI. Silviculture and biology of short-rotation woody crops in temperate regions: then and now. Biomass and Bioenergy 2006;30:696-705.

[21] Coyle DR, Coleman MD. Forest production responses to irrigation and fertilization are not explained by shifts in allocation. For Ecol Manage 2005;208:137-52.

[22] Henneberger TSM, Stevenson KL, Britton KO, Chang CJ. Distribution of Xylella fastidiosa in sycamore associated with low temperature and host resistance. Plant Dis 2004;88:951-60.

[23] Williams JE, Woinarski J. Eucalypt ecology. Cambridge, UK: Cambridge University Press; 1997. p. 211.

[24] Myers BJ, Theiveyanathan S, O'Brien ND, Bond WJ. Growth and water use of Eucalyptus grandis and Pinus radiata plantations irrigated with effluent. Tree Physiol 1996;16:211-9.

[25] Davidson NJ, Battaglia M, Close DC. Photosynthetic responses to overnight frost in Eucalyptus nitens and E. globulus. Trees Struct Funct 2004;18:245-52.

[26] Rockwood DL, Carter DR, Langholtz MH, Stricker JA. Eucalyptus and Populus short rotation woody crops for phosphate mined lands in Florida USA. Biomass and Bioenergy 2006;30:728-34.

[27] Wells B. Arborgen - Purpose-grown trees for renewable energy. Cold Spring Harbor, NY: President's council: plants, biofuels, and the future of energy. Available at: http://www. rubicon-nz.com/pdf/arborgen_presentation_oct_08.pdf; 2008 [accessed on 23.03.2010].

[28] Rockwood D. Personal Commun; February 20, 2009. Professor Emeritus, University of Florida.

[29] Yu Q, Pulkkinen P. Genotype-environment interaction and stability in growth of aspen hybrid clones. For Ecol Manage 2003;173:25-35.

[30] Glover G, Quicke H. Growth response of loblolly pine, sweetgum, and water oak in a pine-hardwood density study. Can J For Res 1999;29:968-78.

[31] Volk TA, Abrahamson LP, Nowak CA, Smart LB, Tharakan PJ, White EH. The development of short-rotation willow in the northeastern United States for bioenergy and bioproducts, agroforestry, and phytoremediation. Biomass and Bioenergy 2006;30:715-27.

[32] Willebrand E, Ledin S, Verwijst T. Willow coppice systems in short rotation forestry: effects of plant spacing, rotation length and clonal composition on biomass production. Biomass and Bioenergy 1993;4:323-31.

[33] Albaugh TJ, Allen HL, Dougherty PM, Johnsen KH. Longterm growth responses of loblolly pine to optimal nutrient and water resource availability. For Ecol Manage 2004;192: 3-19.

[34] Allen HL, Fox TR, Albaugh TJ. Productivity and nutrient management concepts and fertilization practices in southern pine plantations. Raleigh, NC, and Blacksburg, VA:
Forest Nutrition Cooperative, North Carolina State University and Virginia Polytechnic Institute and State University; 2004.

[35] Jokela EJ, Dougherty PM, Martin TA. Production dynamics of intensively managed loblolly pine stands in the southern United States: a synthesis of seven long-term experiments. For Ecol Manage 2004;192:117-30.

[36] Wann SR, Rakestraw JL. Maximizing hardwood plantation productivity in the southeastern United States-lessons learned from loblolly pine. Conference proceedings, December 1-3, 1998. In: Ek AR, ZumBahlen B, Compilers, editors. Improving forest productivity for timber, a key to sustainability. Duluth, St Paul, MN, USA: University of Minnesota; 1999.

[37] Siry JP, Robison DJ, Cubbage FW. Economic returns model for silvicultural investments in young hardwood stands. South J Appl For 2004;28:179-86.

[38] McTague JP, O'Loughlin D, Roise JP, Robison DJ, Kellison RC. The SOHARC model system for growth and yield of southern hardwoods. South J Appl For 2008;32:173-83.

[39] Smith BW, Miles PD, Vissage JS, Pugh SA. Forest resources of the United States, 2002. St. Paul, Minnesota: USDA Forest Service North Central Research Station; 2004.

[40] Schuler JL, Robison DJ. Stand development and growth response of 1 to 6 year-old natural upland hardwoods to silvicultural treatments. For Ecol Manage 2006;232:124-34.

[41] Romagosa MA, Robison DJ. Biological constraints on the early growth of hardwood regeneration in upland Piedmont forests. For Ecol Manage 2003;175:545-61.

[42] Stanturf JA, Portwood J. Economics of afforestation with eastern cottonwood on agricultural land in the lower Mississippi alluvial valley. Shreveport, LA, USA: Tenth Biennial Southern Silvicultural Research Conference; 16-18 February, 1999.

[43] US Biomass Research and Development Interagency Board. Increasing feedstock production for biofuels: economic drivers, environmental implications, and the role of research, http://www.brdisolutions.com/Site\%20Docs/ Increasing\%20Feedstock_revised.pdf; 2008 [accessed on 23. 03.2010].

[44] Johnson TG, Steppleton CD. Southern pulpwood production, 2005. Research Bulletin SRS-101. Asheville, NC: USDA Forest Service Southern Research Station; 2007.

[45] Cubbage FW, Wea DN, Bennadji Z. Economic prospects and policy framework of forest biotechnology for the southern USA and South America. In: Williams CG, editor. Landscapes, genomics, and transgenic conifers. New York: Springer; 2006. p. 191-207.

[46] Schuler JL, Robison DJ, Quicke HE. Assessing the use of chopper herbicide for establishing hardwood plantations on a cutover site. South J Appl For 2004;28:163-70.

[47] Borders BE, Will RE, Markewitz D, Clark A, Hendrick R, Teskey RO, et al. Effect of complete competition control and annual fertilization on stem growth and canopy relations for a chronosequence of loblolly pine plantations in the lower coastal plain of Georgia. For Ecol Manage 2004;192:21-37.

[48] Robison DJ. Development of baseline information to understand dieback and decline diseases in sycamore plantations in the southeastern U.S. Athens, GA, USA: USDA Forest Service Southern Research Station; 2001.

[49] McTague JP, Young M. Growth and yield of sweetgum and sycamore plantations. Raleigh, NC: North Carolina State University Hardwood Research Cooperative; 1997.

[50] U.S. National Arboretum. The 2003 US National Arboretum 'Web Version' of the USDA Plant Hardiness Zone Map; based on USDA Miscellaneous Publication No. 1475, Issued January 1990. U.S. National Arboretum, Agricultural Research Service, U.S. Department of Agriculture, Washington, D.C. Available at: http://www.usna.usda.gov/Hardzone [accessed 23.03.2010]. 